\title{
GTN - INFORMATION SYSTEM SUPPORTING THE DISPATCHER AND REMOTE TRACKS CONTROL
}

When constructing new corridor tracks, but also when reconstructing the existing ones of all categories, new significant improvements and innovations occur in the contruction area. Consequently, the same phenomenon occurs in the newly installed securing, interlocking and signalling equipment, and generally enabling also remote track control. The traffic information and controlling system (hereinafter the GTN) being developed by the Software Technologies Department of the University of Zilina in cooperation with the AZD Praha Company, represents a graphical and technological extention of the electronic signalling equipment. It contains a compact data, technology and software model of railway operation, enabling to receive information from the securing, interlocking and signalling equipment, as well as from other information and controlling railway systems, about trains' movement. It also enables to save, display and document the traffic progression, trains movement and technological operations on them. Last but not least, it provides opportunity to display the anticipated prognosis of the traffic situation, and transmit information about trains movement towards external IS, e. g. the passenger information systems at the stations etc.

Currently, the GTN system has been implemented and used in several versions on the Czech and Slovak Railways tracks. Hereby we would like to introduce its latest solution based on distributed architecture using a database system.

\section{Introduction}

In the Central Europe countries, construction works associated with modernizing or building railway tracks belong to the largest construction projects of current times. This corresponds to the amount of the investments needed. Therefore, it would be a disappointment and loss, if using the tracks were devaluated by low quality of transport technologies following the construction part. As a rule then, in both, the Czech and Slovak Republic the modernized tracks have been equipped with a modern security remote-con- trolled signalling equipment (hereinafter DOZ - remote centralized traffic control). It enables to control railway traffic from various workplaces many tens of kilometres distant from each other, and to centralize transportation processes control.

By 'control' we mean the possibility of organizing traffic by means of determining the train runs order, their overtaking, using station and track rails etc. At the centralized dispatcher places (CDP), the controlling process is connected directly to the electronic interlocking control, or stations security signalling equipment

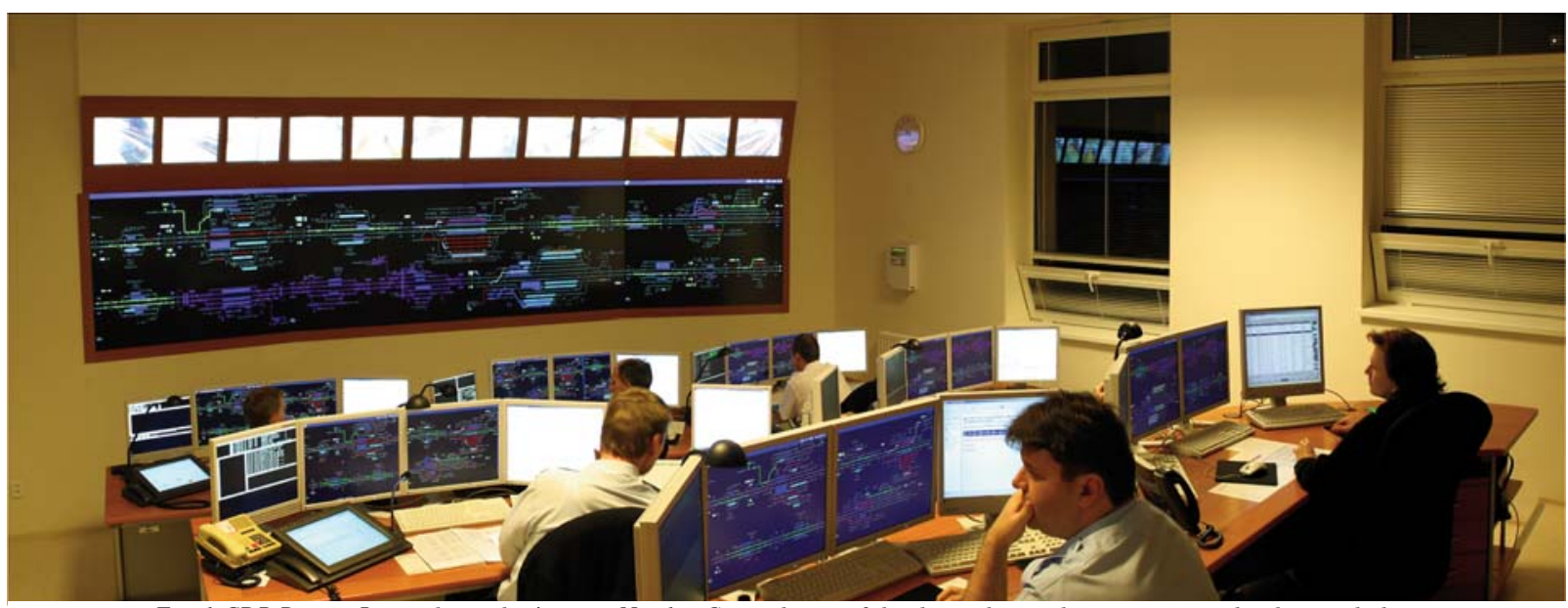

Fig. 1 CDP Prerov, Large dispatcher's room No. 1 - General view of the dispatcher and operator centralised control place

\footnotetext{
* Emil Krsak ${ }^{1}$, Hynek Bachraty ${ }^{1}$, Vlastimil Polach ${ }^{2}$

${ }^{1}$ Department of Software Technologies, Faculty of Management Science and Informatics, University of Zilina, Slovakia, E-mail: emil.krsak@fri.uniza.sk

${ }^{2}$ AZD Praque, Czech Republic
} 
control respectively. This includes, e. g., creating the train routes through particular stations, entering the information on anticipated departures or specifying some events, such as a train origination, expiration and renumbering, shifting at the station etc.

The way the operating staff workcombines the train and station dispatchers' activities. The software controlling the signalling equipment is usually able to supervise and change the state of the infrastructure individual elements, to supervise the rails occupation by train vehicles, and to identify in the occupation changes the individual trains movement.

In Slovakia, tracks modernizing has still been in the initial phase but in the Czech Republic it already started in the half of the 90's. The fact that dispatcher places originating at modernized tracks were equipped with computer technologies, interconnected by a reliable network and operated by computer-skilled staff, was very inspirational for further development. In that period the AZD Praha company addressed the Software Technologies Department of the University of Zilina, suggesting to develop and implement an information system using and developing possibilities of a modern securing, interlocking and signalling equipment. On the basis of the requests we developed the GTN - an information system to support the DOZ's dispatcher's decision-making processes. The GTN stands for graphic-technological extension of the signalling equipment. The system has been directly connected to the electronic ESA interlockings by the AZD Praha, supplied to a new corridor and later also to other tracks.

Since the first GTN version was implemented, eight years have already passed, and currently the system works on hundreds of kilometres of tracks controlled by the AZD Praha signalling equipment. In our article we are going to concentrate on the GTN latest version implemented e. g. at the international corridor track (OBB/, ZSR) Breclav - Prerov - Petrovice (/PKP), e. i. VI. TEN corridor in the Czech Republic. Technical, technological and operational aspects of the transportation centralized control on the Prerov - Břeclav track (CDP Prerov) are introduced in [5]

\section{Technological links and GTN usage}

The main role of the GTN system is to gain, identify and interpret data on trains runs from the connected $\mathrm{DOZ}$ as well as from other sources. It can document, archive and display the information for the operation staff in a transparent way, including displaying the traffic prognosis. The system also sends out some of the acquired information into other systems. The grounds of the GTN activities is the data model of one-train run, and the traffic situation model created from trains runs and network description. The current transport plan has been acquired from the data of the SENA and ZONA systems, being developed also at the Software Technologies Department of the University of Zilina, and used by the Czech Railways (CD) and Slovak Railways (ZSR) to construct the train time-table plans.

The GTN is a system supporting the decision-making process related to controlling transportation processes. Displaying the traffic prognosis has been its significant part. Another one is disburdening the operation staff from routine and duplicate works (conducting documentation, sending identical information into several systems, confirming the announcements reception and so on), by which the dispatcher gains time for the decision-making itself. What is also important is to ensure automatized, fast and precise information transfer.

From the viewpoint of activities, it is possible to divide the work done by the GTN into four basic fields which we are about to describe briefly below.

\subsection{Information entering the GTN from the electronic signalling equipment}

The main entry of the data about current traffic for the GTN is provided via communication with some type of electronic interlocking installed by the AZD Praha Company. From the controlling interlocking we are able to gain information on the trains numbers movement in a so called stacks, corresponding to the individual station and track rails. First, the train number appears in them, then it changes some of the specific state signs, and, finally, it frees the stacks. Except that, in some situations we also acquire an information on the kind of action the interlocking operation staff have performed. We use the information to put together the data about the train run. A standard procedure in each station is creating a train route, train arrival, anticipated and actual train departure and freeing the rail. At large, we observe more than 30 different actions on the train, such as the beginning and finishing the train run, sidetracking the train, changing the train route, shifting the train, riding on emergency signal, train-confirming signal, several types of train renumbering, departure and return of the train from the branch line to the track, the train returning from the track, a train-run expiration on the track etc. Correct and precise comparison of time data of the actual and planned rides requires (regarding the disunited methodology of various units of the railways) to work in some of the time and data corrections of the acquired information.

Although the GTN system also enables manual entering of the train run information, this is just a backup in case of interlocking or communication with interlocking fail. The ability to gain all of the train run data in the controlled area automatically, without the necessity of the operation staff's assistance, represents a significant element in the effectiveness as well as punctuality and reliability of their work. Moreover, the data acquired from the signalling equipment, which, to make sure it works correctly, has to observe the train movement duly, are unimpugnable and demonstrably precise. Thus the seminal traffic documentation of new quality originates.

\subsection{Information entering the GTN from the all-state raiway network and external IS}

Communication with the $\mathrm{DOZ}$ enables automatic acquisition of the train run information until the moment the train occurs in 


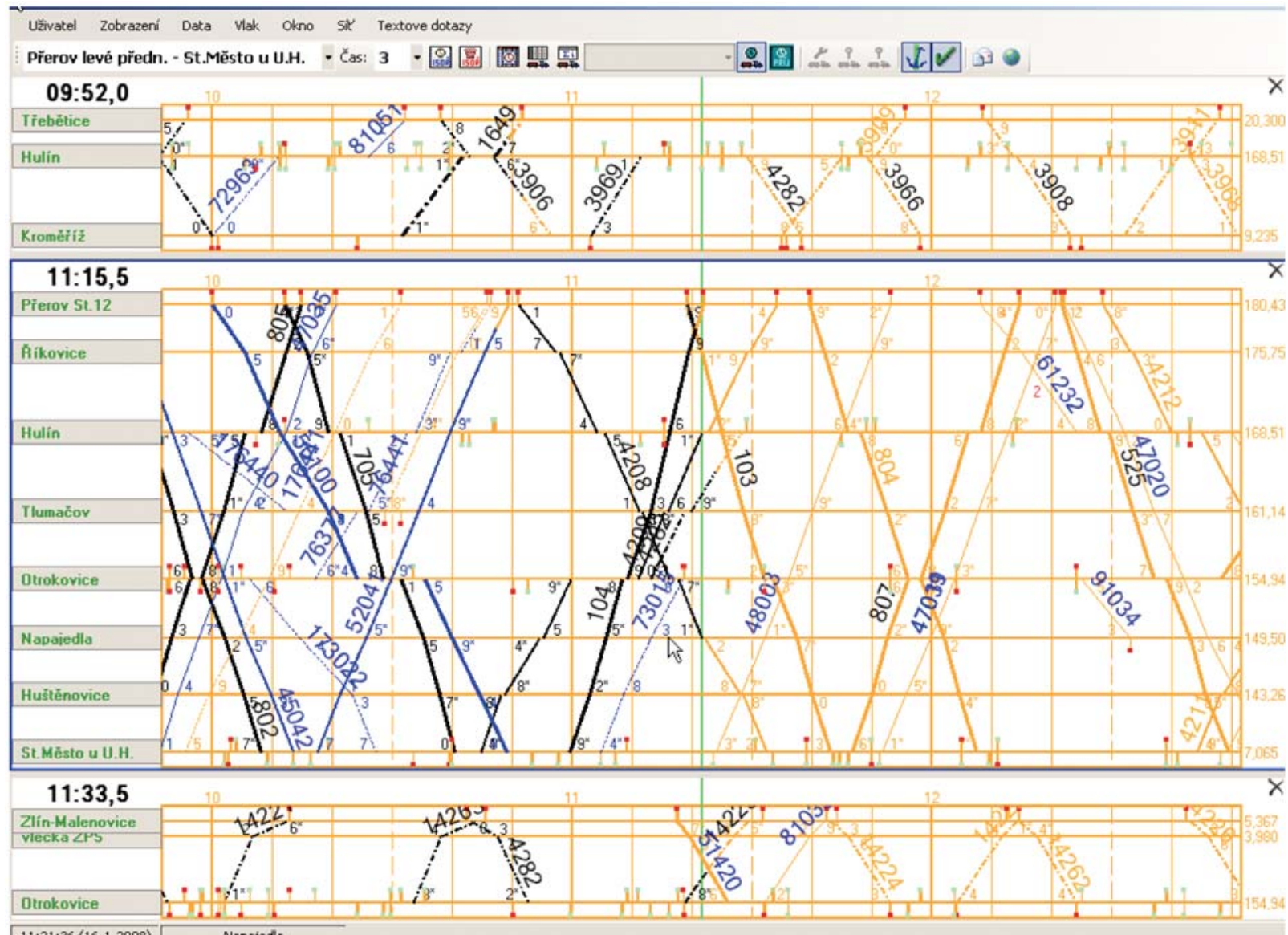

Fig. 2 Displaying the main and side tracks in the controlled area of Breclav-Prerov

the controlled area. Therefore, another extention of the GTN possibilities in the Czech and Slovak Railways environments was to interconnect the system with the all-state railway network information systems for freight and passenger transport (ISOR, CDS, PIS, EDD). This enables us to gain information on the train and its run from the moment it has been planned to the arrival at the controlled area. The most important information are as follow:

- information whether a particular train operates today which we react to by installing it into perspective traffic. This applies mainly to freight transport; with passenger transportation we prefer to refer to the train operation calendar.

- some of the train parameters, such as, e. g. its weight, length, driving vehicle, engine crew, TIN (train identity number) etc.

- current train delay and the station of the latest known train event

- planned operations on the train in the controlled area (terminating the run, sidetracking the train, renumbering the train and so on).

- anticipated and actual departure time from the station neighbouring with the controlled area.

\subsection{Evaluating, retaining and presenting the transportation situation}

The acquired data are saved into the traffic data model which is presented to the operation staff in several ways. The basic ones are as follow:

- a two-parts train control diagram displaying following information: fulfilled traffic and perspective traffic, containing its prognosis. Except the train routes locations themselves, to display their attributes we have also used other graphical and interactive means. The individual line segments are defined by operation staff, they can be displayed in different modes, forms and numbers.

- train data record, picturing time information on its run, used rails and some important technological events. The train diagram and train data record contain actual time data compared with the planned ones, it is possible to display the differences.

- summary information on the train, picturing the train technical parameters.

- events protocol for the controlled area capturing all important events in the traffic and the GTN servicing.

- number of internal protocols capturing in detail the GTN system operation, its communication, operation staff activities etc. 


\begin{tabular}{|c|c|c|c|c|c|}
\hline \begin{tabular}{l|l|l|l|l|}
0 & (1) & $\mathbf{T}$ & @ & $\diamond$ \\
\end{tabular} &  & Ed | Předávka dopravny | Odevzdávka služby & (3) Filtr & & \\
\hline Kdy & Vlak & Událost & Dopravna & Druh & Cas/Info/Dúvod \\
\hline (2) $17.4 .2007 .12: 40: 12$ & $614(1)$ & Odjezd na Tk 2 & Hájek & $z$ & korekce -25 sekund \\
\hline (2) $17.4 .200712: 40.12$ & 614(1) & Odjezd Sk 2 & Hójek & $\pi$ & korekce .25 sekund \\
\hline (2) 17.4.2007 12.40:12 & $614(1)$ & Odjezd na Tk 2 & Hâjek & $\bar{z}$ & korekce $\cdot 25$ sekund \\
\hline 017.4.2007 12.40:21 & $614(1)$ & Uvolnẻni Sk 2 & Hajek & $\overline{z z}$ & . \\
\hline 7. $17.4 .200712 .40: 21$ & . & Vlak/PMD 999901 dojel do Chodov zhlavi cely. & $\mathrm{KV}$ - staniční & č.327 & . \\
\hline 17.4.2007 12:40:44 & $17110(1)$ & Odjezd Sk 2 & Karlovy Vary & Zz & korekce -30 sekund \\
\hline (2) 17.4 .200712 .40 .50 & $17110(1)$ & Uvolnèni Sk 2 & Karlovy Vary & $\bar{z}$ & . \\
\hline (2) 17.4.2007 12:41:09 & $7057(1)$ & Minuti vináv. na TK 1 & Stráż nad Ohríi & $\bar{z}$ & . \\
\hline Q17.4.2007 12:41:21 & 169932(1) & Minutí vịnáv na TK 2 & Perștein & $\bar{z}$ & . \\
\hline (3) $17.4 .200712 .41: 21$ & $169932(1)$ & Minuti vịnáv na TK 2 & Perštein & $\bar{z}$ & duplicita \\
\hline 2017.4.2007 12:41:35 & $66712(1)$ & VCSk 2 Tk 2 & Klášterec nad Ohři & $\bar{z}$ & . \\
\hline (3) 17.4.2007 12:41:42 & 7057/11 & Viezd Sk 2a & Stráž nad Ohří & $\pi$ & . \\
\hline
\end{tabular}

Fig. 3 Events protocol in the controlled area of Karlovy Vary

These means enable to display the current situation and, at the same time, to create, administer and show archive information describing the traffic within the elapsed hours and days. The data are transferred into archives gradually, in a certain interval after the train run has finished, or after it has departured from the controlled area. The traffic perspective part, except the possibility of following the routes of actually operating trains in their current time positions, also contains an algorithm for searching conflict transportation situations and their proposed solutions.

The key to the GTN importance is that this system of storing traffic information has been certified for the Czech and Slovak Railways as a full-value way of traffic documentation (so called ELDODO, traffic electronic documentation). Operation staff is thus free from a lot of manual work (keeping a transportation diary, drawing the fulfilled train diagram etc.), and they are able to concentrate entirely on controlling the traffic.

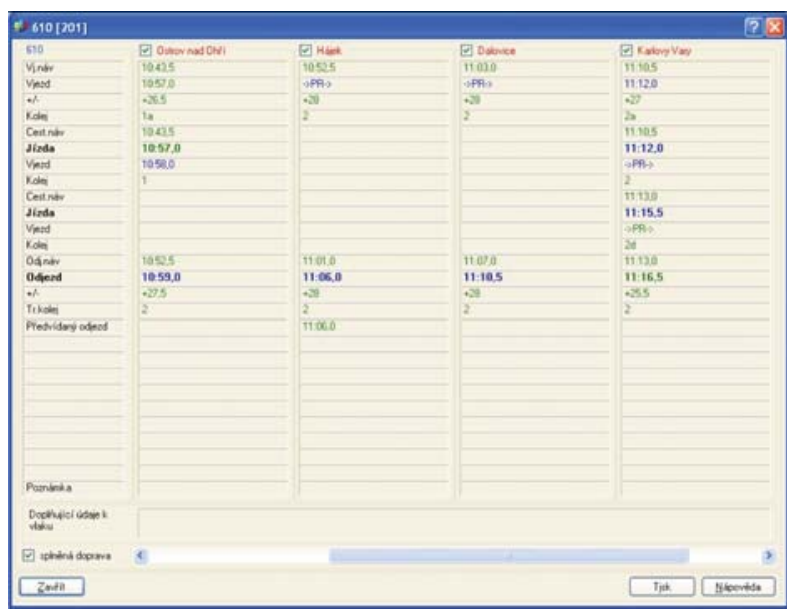

Fig. 4 Train data record on the train No 610 - precise description of the train run

\subsection{Sending information into other IS}

Precise train run data in the controlled area acquired in real time from an electronic interlocking are so called 'attractive infor- mation'. They serve as input data for many other systems. If they needed to be entered manually, a remarkable part of the GTN system benefit would get lost. That is why we, except working in the entry information, generate automatic outputs, too.

First of all, there are already mentioned ISOR, PIS and EDD systems into which we send detailed information on trains arrivals, departures and crossings (times, used rails, correction message sign, reasons for breaching timetables etc.). The information serve the operation IS, managerial systems (as well as to specifying the fee for using the transportation route), the GVD analysis etc.

We send the information on the train arrival and departure, as well as on the creating of the arrival and departure route in the station into the INISS system, which provides voice and visualizing information for passengers at the stations. The train announcements for passengers thus correspond to the train actual run. Thanks to the traffic situation prognosis in the GTN, passengers get up-todate and precise information on a train delay, too.

Another system which the GTN communicates bidirectionally with is the ASDEK system for measuring some of the physical entities of the running train. It is so called vehicle diagnostics of a running train by means of the firing indicator, flat wheels indicator, hot bearings indicator etc. The ASDEK system, after the train has passed the check point, sends a resulting diagnostics report on the train to the GTN; the GTN gets back to the ASDEK with the number of the train the report concerns, for further processing and archivation. In case the train has been diagnozed with a defect, the GTN initiates an alarm and displays a warning window with detailed information (the train number, the defect character and extent, the axis number, the train side and others) which the dispatcher has to react to.

The GTN also enables voice services for the connection to the train engine driver. Thanks to the voice communicator, it is possible, directly from the GTN environment, to get connected to the train or other participants. In the Czech Republic, the GTN has been implemented with the IPR-Communicator by the CDTelematika Company; their communicator communicates in the GSM-R and GSM-P environments.

Except the above stated data links, the GTN enables a direct access to the portals of operation control in the railway intranet 
network. Therefore, there is an access to the GVD tools, layoffs IS, freight transport IS - CEVIS/WIC, information boards, ISPR RVD - planning, ISOR CDS - trains timetables-related positions. Another extending element is the possibility to send from the GTN text parametered inquiries on trains (shift plan, train analysis etc.) into the operation control system, so, immediately it gains further detailed information for transportation control. This way, the GTN user has at disposal a great number of information sources for its work, including electronic mail.

Our system architecture is open and modular. Hence, it is possible to create connections to new systems, and to extend the existing ones. What guarantees good possibilities of the GTN system further development is its modern software design and the solution we describe below, in the up-coming parts of the article.

\section{Hardware and network architecture and communication}

During the existence of the IS GTN the demands on its functionality and usage range have been constantly increasing. From the original requirement to create a single-purpose application to watch and record transport within a two-to-three stations track section, we have gotten to the current shape of a complex information system for large track sections. That is why the IS GTN has gone through several development stages. They corresponded to the various system architectures the system had been built on in the individual stages. The current architecture is based on a wide analysis of all up-to-now used aproaches, on evaluating their positives and negatives, summarising the existing functionalities, as well as on future functionalities estimated on the grounds of experience. The aim has been to create a significantly innovated information system built on integrated modules which would communicate with each other. At the same time, their development is relatively mutually independent, maintaining the communication interfaces functionality.

The architecture is built on distributed applications with a quadruple of efficient central servers. The servers are divided into the main and backup branches, where in case the main branch should fail in any way, the backup branch takes over. One of the two servers is a database server, the other one performs as an

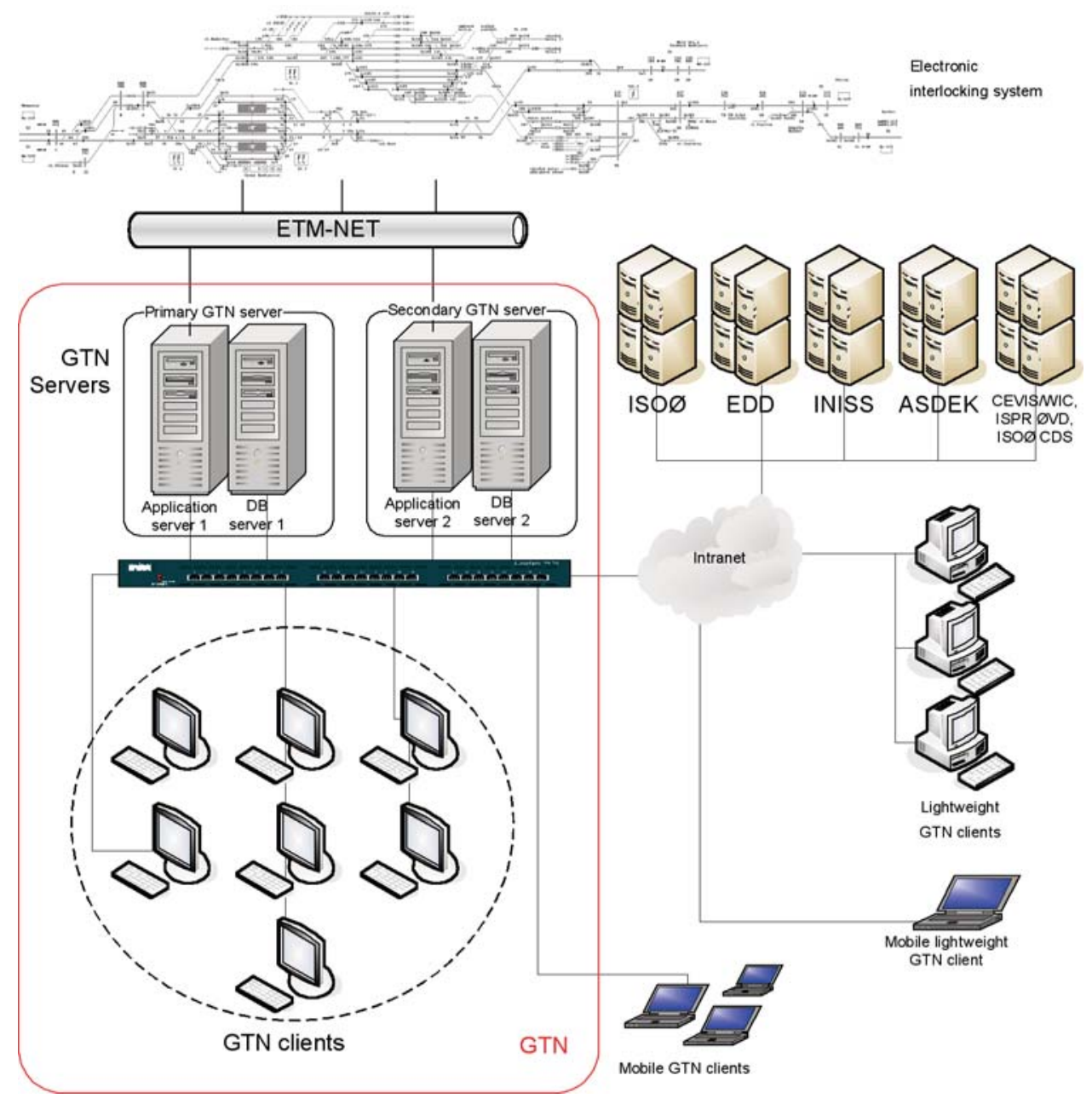

Fig. 5 Architecture of GTN and interconnection to other systems 
application server. On the dispatcher's computer the application server's client is running, offering all of the presentation module functions, and containing all of the functions the dispatcher needs to work with the GTN system.

From the viewpoint of communications, the system is based on a fully distributed model. Communication protocols have been designed in such a manner so that they can transmit events and data changes in form of objects. Regardless the event source (train position change, change of state of the signalling equipment element, dispatcher's entry information from an external information system), each event is processed by a relevant module and it is transformed into a data-change event. Consequently, the event is distributed into each part of the system which the change is relevant to. Thus we have achieved that the data are processed and saved into the database in real time and, at the same time, every change is immediately reflected in all the modules, whether it is a part of application server or dispatcher's client. It all results in a dynamic system actually working in real time. The information on the traffic and signalling equipment elements state are permanently at the dispatcher's disposal. As soon as the values of the data displayed in tens of windows at various worksites change they are instantly updated.

From the viewpoint of functionality, the whole system consists of three main modules as introduced below. Each of them has a specific internal architecture, depending on the module application logics.

\subsection{Module of communication with the EZZ}

The module is supposed to provide communication between the signalling equipment and other parts of the system. The essential thing is to have managed communication protocols and formats conversions. The module core consists of complicated algorithms, which, on the grounds of the current state of train numbers stack, elements, signalling equipment operating personnel's commands and up-to-now traffic progression, determine the individual train-run events. The information get to the rest of the parts of the system in a form which has been within the framework of the system standardized into a communication interface.

The module is the only one which gets in direct contact with the electronic signalling equipment (EZZ). All of the EZZ specifics are closed in the module. This enables the whole system to be relatively independent on the type of electronic signalling equipment. In case the EZZ changes in any way or develops or is replaced completely, it is sufficient to readjust the module, while the rest of the GTN system parts remain fully functional.

\subsection{Traffic electronic documentation module}

The transportation electronic documentation (ELDODO), as it has been mentioned already, constitutes one of the main functionalities of the entire system. It consists of several components which the operating personnel will deal with mainly when presenting the transportation situation mentioned in Part 2.3. Detailed information are saved in the database in various forms :

- Trains data. In the system each train is represented by a data object which collects data about the train's planned route, the train's actual operation and movement, and about the operations carried out on the train. It is possible to display the information in a graphic form in a train diagram, in the text train data record collecting information on the train run, or in the train parameters window.

- Operating activities protocol which stores information on the dispatcher's interventions into the signalling equipment or GTN, and on the manner in which they have been worked into the trains data.

- Data about the communication with external IS which inform about the information received from and sent to external information systems.

- Internal protocols which record information on the system state and its activities that influence the system's behaviour, help solve unexpected states afterwards and harmonize the whole system's performance.

\subsection{Module of communication with external IS}

The module is responsible for mutual communication with external information systems of the operation control, which the GTN takes information from or which the GTN sends information to. The module consists of several smaller modules created individually for each type of an external IS. The sub-modules differ from each other by the communication interface specifics, by the transmitted data formats and structures, and by the ways the data are worked in. Currently, there are following sub-modules:

- Communication with the operation control information systems ISOR, CDS and PIS

- Communication with the station dispatcher's system EDD.

- Communication with the INISS, which is a system for station automatized train arrivals and departures voice announcements for passengers.

- Communication with the ASDEK system which is a track system for contactless monitoring of bearings temperature, wheel rims, circular brakes discs and irregularities on the wheels perimeters at the moment of the train passing by the device.

The ISOR, CDS, PIS and EDD systems are communicated with on the basis of telegrams of precisely defined formats which are used by several applications utilized by CD and ZSR. The INISS system is communicated with by means of WebServices and the SOAP. A specific communication protocol has been designed and implemented for the ASDEK system.

\section{Software and databasis solution}

The growing demands on the system functionality have been reflected also in the system software implementation itself. The current version needed to solve several essential, and, to certain 
extent contradictory, requirements, which did not play a crucial role when the first versions had been designed. They are simplicity and transparency of the system, large scope of the controlled area, and data basis standardization. All of the demands have been interconnected very closely, and solving one of them has an impact on solving the others.

The goal was to create an architecture which would, in as an optimal way as possible, sort out the requirements placed on the system, and which, at the same time, would not be too complicated from the viewpoints of technology and logics. The design stems from a standard linear multi-layer architecture consisting of several basic layers:

- Data persistence

- Data access

- Data manager

- Client's and server's application logics

This solution has increased the possibilities of the system's further modification and extention, and it supports its distributivity.

The controlled area range, attachment to other external information systems and the data standardization requirement have been the reason why the IS GTN has moved from its own datapersitence management to using a database system. Yet, the architecture remains independent on the data-persistence system, and it is possible to be replaced by implementing another layer of data access.

The logic layer is responsible for the access to the lowest datapersistence layer. It hides the complexity of the access to the physical data storage from the rest of the layers. The key point of this part is its interface design. The interface helps the system gain the data access, and it should be universal, not too complicated. Its design ought to take into consideration various data-storages systems.

The data manager represents the main core of the system. Its modules ensure creation of serialized data entities which are used with data-transfers between application layers. At the same time the manager also functions as an administrator of data-objects collections, and coordinates the communication between the layers.

The application logic layer implements the IS GTN functionalities, i. e. the server as well as client parts of the system. It implements the interface between the user and the system, as well as between external systems and the IS GTN. Paralelly, it processes these user entries and external events, and generates system's relevant reactions.

\section{Reasons to the control centralization, and its advantages}

Railway traffic management depends on the range, punctuality and timeliness of the required information transfer. As long as finding, collecting and processing the information are dependent on a human factor exclusively, they are limited by its abilities. This brings along a high number of employees participating in the controlling process, and low effectivity of their activities. Therefore, in order to improve the quality of railway traffic control, it is necessary to use better ways of processing and utilizing the information flows, to employ modern means of communication, securing and information technologies.

Railway transportation control originates from the way the signalling equipment is operated. The device type determines how work is organized with the operation running itself. The ways of work are very different, and they have a significant influence on the railway traffic safety. It is an advantage to have good knowledge of the whole route/track section. This requires the employee-in-charge to have a good overview of the situation, which cannot be ensured by the individual station dispatchers. The need of controlling larger technological area units comes along also with the trains speed on the track, namely on the tracks serving different types of trains with remarkably different ride speeds.

The railway traffic remote control requires to create a workplace where all necessary technologies have to be concentrated. It is apropriate to place the employees in charge of neighbouring sections, or of one technological unit, into one control site (central dispatcher workplace - CDP), which will provide perfect overview of the traffic situation on the individual tracks/routes.

The CDP has been created as a workplace for train traffic remote control in controlled areas. The CDP consists of dispatcher centres for the individual controlled areas. A dispatcher centre constitutes a complex of operating and other workplaces of all function positions of the employees in charge of a given area. They are: operation dispatcher, controlling and section dispatchers (DOZ dispatchers), traffic operators, dispatcher of railway transport route functionning (technical infrastructure). One of the components of a transportation hall might be an overview display of the controlled area on large screening units.

The DOZ dispatchers directly control the traffic within the allocated part of the controlled area, and they remotely control the signalling and iterlocking equipment. The number of the DOZ dispatchers on duty may change, depending on the train traffic density. The number of service workplaces of the controlled area signalling equipment has to be relevantly sized to the maximum expected train traffic volume. Various operation personnel combinations and division of the controlled area into the DOZ dispatchers' districts are determined by the service plan. Last but not least, operation employees reduction, namely at the stations, has been a considerable benefit of the control centralization.

The way a long track section is controlled needs to respect also the local operation-technological processes. Among limiting factors, there is an ability of one employee to manage the operation of their allocated area. Further on, the communication connections to another workplaces participating in the controlling process have to be elaborated, especially connections to the station dispatchers 
of all of the stations neighbouring with the controlled area. One must not forget about specific demands on the communication equipment. The essential thing is a connection between the DOZ dispatchers, the controlled stations and entry stations, switchable in accordance with the controlled station mode in remote or local operation. Next, there is a need of local radio networks to connect with working teams in the field (shifting, infrastructure maintenance) and the track radio system (GSM-R) to connect with the train engine driver. What is also important is the passengers information system, or the carriage diagnostics system of the trains currently moving on the tracks.

Delegating the control of the individual stations signalling equipment to one central dispatcher workplace represents a breakthrough in the transportation processes effectiveness and quality. Implementing new technologies enables to change the track section controlling technology significantly. The control of train traffic within larger track units, including the single-route, branching or train-creating stations, brings along higher effectivity of the decision-making processes. A model of control like this might include all key transportation elements. To make also the management of large track units as operative as possible, it is necessary to apply correctly the supporting technical and telematic means and transportation technologies. The signalling equipment remote control with a direct connection to the information and management systems of the railway transport enables the ultimate usage of the information flows related to the transport processes management. Therefore, the information and control system GTN has its irreplaceable position in the systems architecture in the area of a track operation.

\section{Implementing the remote control on the CDP Prerov for the track Prerov - Breclav}

The international corridor track Breclav - Prerov is a pilot project of implementing the latest GTN system version, as well as one of the first central workplaces of remote control.

The centralizied control of the track Prerov - Breclav was solved as one controlled area. Since March 2007 the track has been con- trolled from one CDP dispatcher centre in Prerov. To exectute remote management of the signalling and interlocking systems of all fifteen stations they have been using the AZD DOZ 1 system, i. e. remote control with emergency servicing and with backed-up communication branches. The dispatcher commanding computer has been complemented by a range of specific servicing functions related to the control of a large controlled area. They are, e. g., automatic turning of a track approval according to a given train route or building a train route over more stations by one dialing. The transmission of train numbers in the station and track rails relief is commonplace. The signalling equipment control corresponds to the basic technical requirements on the unified active control place. The AZD DOZ 1 remote control is complemented by the GTN application which automatically keeps the transport electronic documentation, displays current and perspective traffic situation, datacommunicates with higher information and controlling systems of the railway transport. The GTN provides the access to selected portals of the operation and operative control in the CD intranet. Thus all of the important information are available within one system, either directly or by request.

At all entry stations of the track Prerov - Breclav, terminals for train numbers insertion and their anticipated and actual departures have been installed. Therefore, the mutual data communication has fundamentally minimalized the DOZ dispatchers's voice communication with the employees-in-charge of the entry stations when negotiating the train rides.

A large display of the whole-track trackage is solved in a form of backed-up individual serviceless projector equipment. Four displaying modules with back projection of a $67^{\prime \prime}$ diameter and placed into a row next to each other are used. Above them, there are 12 LCD monitors to display subways and platforms from the camera systems. There are more than 80 screening cameras all over the track. The individual pictures are switchable.

The dispatcher centre of the controlled area of Prerov - Breclav is shared by the traffic control dispatchers and transportation operators; the traffic route functionning dispatchers have an independent room.
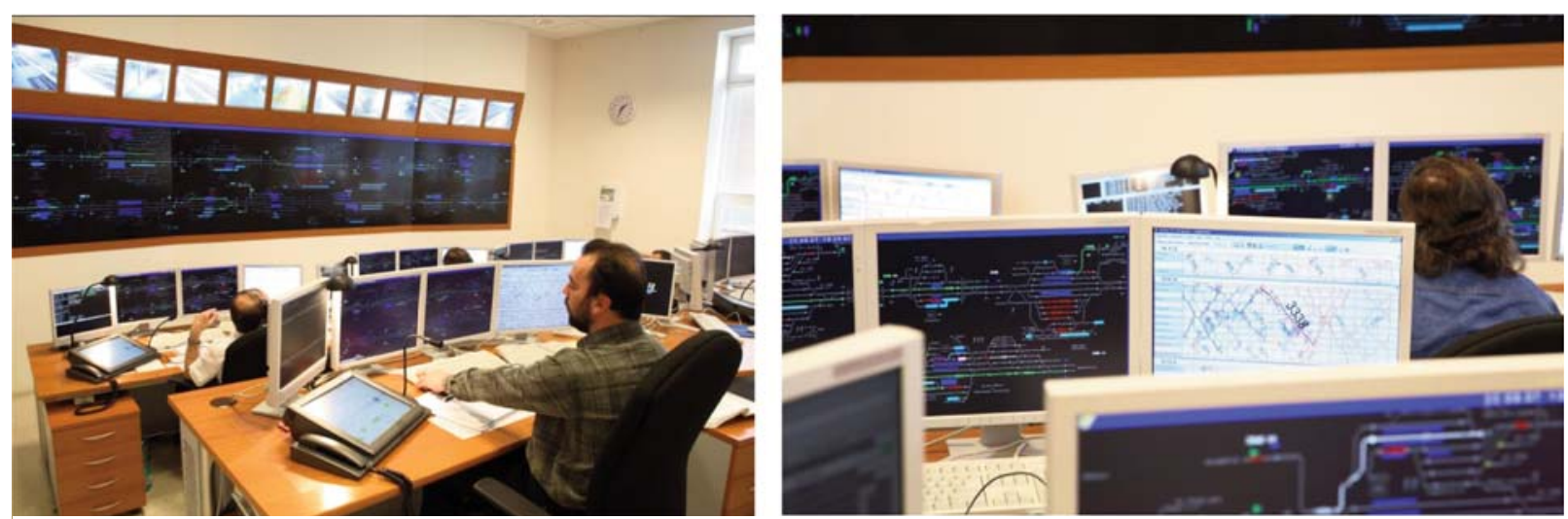

Fig. 6 View of dispatcher workplace in dispatcher room 
The traffic over a $100 \mathrm{kms}$ double-rail track in 15 stations is controlled by two control dispatchers. Three section dispatchers are in charge of local works and operation over 8 sidetrackings. Two operators watch the automatic activities of the passengers information systems and other systems. This is the maximum personnel occupancy. However, there are also variants of lower personnel occupancy, which apply with low traffic volume.

The traffic route functionning dispatcher has at disposal the state diagnostics of the station, track as well as remote signalling and interlocking equipment. Furthermore, they watch the indications of the exchanges electric warming, trackage night lighting, fire alarm, objects securing signalling, platform elevators operation, supplying the traction power lines and signalling equipment. This way, supervizing the track technical systems has been concentrated into one and only workplace.

At four important stations, emergency station dispatchers are based. In case of an emergency they take over. The other stations do not have any transport-controlling staff. However, each station, after it is occupied by a station dispatcher, is possible to control locally.

\section{Conclusion}

Currently the GTN system has been implemented in more than 50 controlled areas of the Czech and Slovak Railways networks. It serves as an extention of the AZD Praha'signalling equipment on nearly $1,800 \mathrm{kms}$ of railway tracks. Except the remotely and centrally controlled tracks, which are described in detail in the above article, it also works on extensive tracks controlled from several stations, on small local tracks, as well as at big nodal stations, such as, e. g., newly reconstructed main station in Prague. The system is supposed to be implemented abroad, too. It needs to be able to react to all differences stemming from the different implementations. Changing and innovating the GTN system is also required due to the need to communicate with more and more new external information systems and further versions of the signalling equipment.
The diversity in the implementation of the system has shown the IS GTN flexibility, and its constant development. This is enabled by its modular architecture, and by using the latest information technologies for its creation. Therefore, GTN represents the combination of a reliable system which, with some tracks, has been working on its own for years, and of a modern application which is able to develop itself and extend the areas of its utilisation permanently.

\section{Abbreviations}

ASDEK - system for measuring some of the physical entities of the running train

CDP - centralized dispatcher workplace

CDS - central dispatcher system

CEVIS/WIC - freight transport IS

CD - Czech Railways

DOZ - remote centralized traffic control

EDD - electronic traffic journal

ELDODO - traffic electronic documentation

ESA - electronic interlocking system

EZZ - electronic signalling equipment

GTN - the traffic information and controlling system

GVD - railway traffic plan

INISS - information system for passengers

ISOR - the information system of operative management for CD

PIS - the information system of operative management for ZSR

SENA - the system for railway traffic plannig for CD

TIN - train identity number

ZONA - the system for the system for railway traffic plannig for ZSR

ZSR - Slovak Railways

\section{Acknowledgement:}

This contribution is the result of the project implementation: Centre of excellence for systems and services of intelligent transport, ITMS 26220120028 supported by the Research \& Development Operational Programme funded by the ERDF.

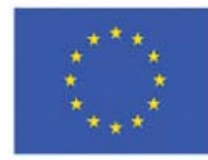

Európska únia
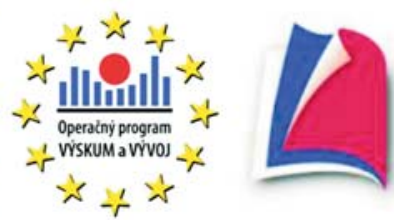

Agentúra

Ministerstva školstva, vedy, výskumu a športu SR pre štrukturálne fondy EÚ

"Podporujeme vyskumne aktivity na Slovensku/Projekt je spolufinancovany zo zdrojov EU."

\section{References}

[1] KRSAK, E., BACHRATY, H., TAVAC, V.: Information System for Railway Control on International Corridor Tracks, Conference EURNEX-ZEL 2006, pp. 68-73, Zilina ISBN 80-8070-547-X. 


\section{COMMNICOIIONS}

[2] ADAMKO, N., SADLON, L.: Application of Network Graphs in Simulation Models of Railway Nodes, Proc. of Intern. conference on informatics technologies in Czech Railways, Infotrans : Pardubice, 2003, ISBN 80-7194-530-7.

[3] SOTEK, K., BACHRATY, H., KRSAK, E.: Simulation Model of Railway Traffic, 36 International Conference MOSIS'02 : Roznov pod Radhostem, 2002, pp. 51-57, ISBN 80-85988-72-0.

[4] SOTEK, K., CHLAN, A.: Research Project Theory of Transport Systems, Proc. of Industrial Simulation Conference 2005, Franhofer IPK : Berlin, pp. 282-285, ISBN 90-77381-18-X.

[5] POLACH, V.: Centralised Control Place Prerov - Pilot Project, In: Conference EURNEX-ZEL 2007, pp. 91-98, Zilina, ISBN 808070-249-7.

[6] TAVAC, M., TAVAC, V.: MDA Transformation of RDB to OODB. In: Conference Objects, Ostrava, issued by VSB - Technicka univerzita : Ostrava, 2007, pp. 96-106, ISBN 978-80-248-1635-7.

[7] TAVAC, V.: Graphic Editor of CD Network Data, Proc. of intern. symposium on Information technologies in transport in Czech Railways : Pardubice, 2002, ISBN 80-7194-419-X

[8] GABOR, M., RUZBARSKY, J.: ZONA and Timetable for Crews for Railways Vehicle, Intern. conference Infotrans 2003, Pardubice : Univerzita Pardubice, ISBN 80-7194-530-7.

[9] HRKUT, P.: Software Support for Creating Railway Graphical Timetable Documents, In: International Conference Infotrans, Pardubice, 2005, ISBN 80-7194-792-X.

[10] HRKUT, P., MATIASKO, K., KRSAK, E., ZABOVSKY, M.: Information Communication System for an Intelligent Transport System, Intern. Conference Manazment v zeleznicnej doprave, Zilina, 2005, ISBN 80-8070-456-2.

[11] URAMOVA, J., BACHRATA, K., KLIMO, M.: Applying Information Theory to Transport Traffic Modelling, In: Infotrans 2007 Pardubice : Univerzita Pardubice, pp. 287-294, ISBN 978-80-7194-989-3. 